\title{
PENGEMBANGAN MEDIA MOONSTAR (MONOPOLI SUPER PINTAR) PADA MATA PELAJARAN IPS MATERI PERKEMBANGAN TEKNOLOGI PRODUKSI, KOMUNIKASI, DAN TRANSPORTASI UNTUK SISWA KELAS IV SEKOLAH DASAR
}

\author{
Dwi Oktaviana Sari ${ }^{1}$, Ali Shodiqin ${ }^{2}$, Ikha Listyarini ${ }^{3}$ \\ Jurusan PGSD FakultasIlmuPendidikanUniversitas PGRI Semarang \\ Email: oktavianasari0804@gmail.com
}

\begin{abstract}
This study aims to describe the media validity level of MOONSTAR (super smart monopoly) and to know learning using media MOONSTAR (super smart monopoly) aided speaking stick teaching model is more effective than conventional learning. This research includes the type of R \& D research and development (research and development) with the research procedure using the ADDIE model. The data collection in this research is done at Analysis, Design, Development, Implementation, and Evaluation. Material and media validation was done by 3 lecturers in each field, and the product trial was conducted on the fourth grade students of SD Negeri Tegalarum 2 Mranggen with 30 students. The result of this research is qualitative data and quantitative data. The validation results by the media expert obtained a score of $92 \%$ (excellent criteria). Expert material validation results obtained a score of $83 \%$ (excellent criteria). Questionnaire teacher response to the media obtained a score of 91\% (criteria excellent). The result of questionnaire of student response to the media obtained a score of $97 \%$ (very good criteria). Student evaluation result by using media MOONSTAR (super smart monopoly) get value of gain equal to 0,51 with medium category. Thus the development of learning media MOONSTAR (super smart monopoly) can be used as a medium of learning and otherwise feasible as a medium of learning.
\end{abstract}

Keywords: Media, Monopoly, IPS, fourth grade students of elementary school.

Abstrak

Penelitian ini bertujuan untuk mendeskripsikan tingkat validitas media MOONSTAR (monopoli super pintar) serta untuk mengetahui pembelajaran menggunakan media MOONSTAR (monopoli super pintar) berbantu model pembelajaran talking stick lebih efektif dari pembelajaran konvensional. Penelitian ini termasuk jenis penelitian dan pengembangan $R \& D$ (research and development) dengan prosedur penelitian menggunakan model ADDIE. Pengumpulan data pada penelitian ini dilakukan pada tahap Analysis, Design, Development, Implementation, and, Evaluation. Validasi materi dan media dilakukan oleh dosen ahli bidang masing-masing sebanyak 3 orang, dan uji coba produk dilakukan pada siswa kelas IV SD Negeri Tegalarum 2 Mranggen sebanyak 30 siswa. Hasil dari penelitian ini berupa data kualitatif dan data kuantitatif. Hasil validasi oleh ahli media memperoleh skor 92\% (kriteria baik sekali). Hasil validasi ahli materi memperoleh skor $83 \%$ (kriteria baik sekali). Angket respon guru terhadap media memperoleh skor $91 \%$ (kriteria baik sekali). Hasil angket respon siswa terhadap media memperoleh skor 97\% (kriteria baik sekali). Hasil evaluasi siswa dengan menggunakan media MOONSTAR (monopoli super pintar) memperoleh nilai gain sebesar 0,51 dengan kategori sedang. Dengan demikian pengembangan media pembelajaran MOONSTAR (monopoli super pintar) dapat digunakan sebagai media pembelajaran dan dinyatakan layak sebagai media pembelajaran.

Kata kunci: Media, Monopoli, IPS, Siswa kelas IV SD 


\section{PENDAHULUAN}

Undang-Undang Republik Indonesia Nomor 20 tahun 2003 tentang Sistem Pendidikan Nasional Bab 1 pasal 1 ayat 1 bahwa pendidikan merupakan usaha sadar dan terencana untuk mewujudkan suasana belajar dan proses pembelajaran agar siswa secara aktif mengembangkan potensi dirinya untuk memiliki kekuatan spiritual keagamaan, pengendalian diri, kepribadian, kecerdasan, akhlak mulia, serta keterampilan yang diperlukan dirinya. Masyarakat, bangsa dan Negara. (UndangUndang Republik Indonesia, 2003: 2).

Peraturan Pemerintah Republik Indonesia Nomor 41 Tahun 2007 tentang Standar Proses menyebutkan bahwa Proses pembelajaran pada setiap satuan pendidikan dasar dan menengah harus interaktif, inspiratif, menyenangkan, menantang, dan memotivasi siswa untuk berpartisipasi aktif serta memberikan ruang yang cukup bagi prakarsa, kreativitas, dan kemandirian sesuai dengan bakat, minat, dan perkembangan fisik serta psikologis siswa. (Permendiknas, 2007: 1).

Ilmu Pengetahuan Sosial (IPS) adalah "ilmu pengetahuan yang mengkaji berbagai disiplin ilmu sosial dan humaniora serta kegiatan dasar manusia yang dikemas secara ilmiah dalam rangka memberi wawasan dan pemahaman yang mendalam kepada peserta didik, khususnya di tingkat dasar dan menengah." (dalam Susanto, 2015:137) dapat disimpulkan bahwa Ilmu Pengetahuan Sosial (IPS) merupakan salah satu mata pelajaran yang penting pada jenjang Sekolah Dasar (SD) yang membahas segala sesuatu yang berhubungan dengan masyarakat.

Hamalik (1986) dalam Arsyad (2011:15), mengemukakan bahwa pemakaian media pembelajaran dalam proses belajar mengajar dapat membangkitkan keinginan dan minat baru, membangkitkan motivasi dan rangsangan kegiatan belajar, dan bahkan membawa pengaruh-pengaruh psikologis terhadap peserta didik.

Media monopoli dipilih karena termasuk suatu permainan yang relatif digemari anak dan mudah dalam memainkannya. Selain itu permainan monopoli layak digunakan sebagai media pembelajaran karena media monopoli ini merupakan salah satu media permainan yang dapat menimbulkan kegiatan belajar mengajar yang menarik, serta mempunyai kemampuan untuk melibatkan peserta didik dalam kegiatan belajar mengajar secara aktif dalam memecahkan masalah yang ada sehingga dapat meningkatkan hasil belajar peserta didik.

Berdasarkan hasil observasi dalam wawancara peneliti di Sekolah Dasar (SD) dijumpai permasalahan diantaranya kurangnya minat siswa dalam proses belajar mengajar. Terdapat beberapa siswa yang kurang memperhatikan penjelasan guru saat proses pembelajaran berlangsung, dan siswa kurang aktif dalam mengikuti pembelajaran dikelas. Kurangnya kreativitas guru dalam mendesain pembelajaran di kelas membuat siswa menjadi jenuh dalam mengikuti pembelajaran. Keberhasilan pembelajaran ini sangat dipengaruhi oleh beberapa faktor diantaranya adalah guru, peserta didik, dan faktor lingkungan.

Selain itu, metode/model serta media pembelajaran juga dapat mempengaruhi proses belajar peserta didik karena media merupakan suatu alat yang dapat membantu kegiatan proses belajar mengajar. Guru sekurang-kurangnya dapat menggunakan alat yang murah dan efisien yang meskipun sederhana tetapi merupakan keharusan dalam upaya mencapai tujuan pembelajaran yang maksimal.

Alasan-alasan di atas tersebut yang melatar belakangi peneliti termotivasi untuk melakukan penelitian pengembangan media yang berjudul "Pengembangan Media Moonstar (Monopoli Super Pintar) Pada Mata Pelajaran IPS Materi Perkembangan Teknologi Produksi, Komunikasi, dan Transportasi untuk Siswa Kelas IV Sekolah Dasar".

\section{METODE}

Penelitian yang digunakan peneliti adalah penelitian dan pengembangan yang 
berorientasi pada produk (Research and Development). Borg \& Gall (1989: 624) dalam Soegeng (2016: 222) mengatakan bahwa "Penelitian dan pengembangan merupakan proses yang digunakan untuk mengembangkan dan memvalidasi produk pendidikan". Penelitian dan pengembangan dilakukan untuk mengembangkan, menyempurnakan, atau memperbaiki produk-produk dan praktik dalam bidang pendidikan. Dalam penelitian pengembangan ini, penulis mengacu pada model ADDIE yang merupakan salah satu model desain pembelajaran sistematik. Menurut Soegeng (2016: 224) model ADDIE terdiri dari lima tahapan yaitu, Analysis (menganalisis), Design (merancang,mendesain), Development (pengembangan), Implementation (mengimplementasi, menerapkan), dan Evaluation (evaluasi). Prosedur ini dapat dijelaskan melalui empat tahap yang telah ditentukan oleh Universitas PGRI Semarang. Tahap-tahap tersebut antara lain: 1). Studi Pendahuluan. Wawancara, Mendesain produk, Instrumen penelitian, Angket untuk lembar validasi ahli media dan ahli materi, dan Angket tanggapan (respon) guru dan siswa. 2). Perencanaan Pembuatan Produk. Menetapkan tujuan pembelajaran, Melakukan tinjauan materi, Pengembangan draff produk, Menyusun sintaks, Menyusun Rencana Pelaksanaan Pembelajaran (RPP). 3). Pengembangan Model. Pengembangan model ADDIE meliputi tahap analysis (analisis), tahap design (perencanaan), tahap development (pengembangan), tahap implementation (implementasi), tahap evaluation (evaluasi). Pengumpulan data meliputi observasi, wawancara tidak terstruktur, kuesioner (angket), dokumentasi. Desain model, Validasi desain dilakukan dengan cara mengadirkan beberapa pakar atau tenaga ahli yang sudah berpengalaman. Revisi desain, dan Validasi perbaikan produk. 4). Pengujian Produk, meliputi waktu dan tempat penelitian, subjek penelitian, uji prasyarat analisis, teknik analisis data dan indikator keberhasilan. Penelitian pengembangan ini bertujuan untuk menghasilkan produk media MOONSTAR (Monopoli Super Pintar) untuk pembelajaran perkembangan teknologi produksi, komunikasi, dan transportasi. Penelitian ini dilakukan pada siswa kelas IV SD Negeri Tegalarum 2 Mranggen. Untuk memperoleh kualitas produk yang baik maka harus melalui uji kelayakan dengan menggunakan angket validasi. Validasi ini dilakukan oleh dosen ahli media dan ahli materi. Kemudian ahli materi dan ahli media menilai kelayakan produk untuk diuji cobakan disekolah. Angket yang dgunakan peneliti yaitu: angket ahli materi, angket ahli medi, angket respon guru dan angket respon siswa. Rumus menghitung presentase dari analisis data:

Presentase $(\%)=\frac{\text { skor } \text { yang didapat }}{\text { skor } \text { maksimal }} \times 100 \%$

Tabel 1.1 Range Presentase dan Kriteria Kualitatif Program

\begin{tabular}{|l|l|}
\hline Penilian & $\begin{array}{l}\text { Kriteria } \\
\text { Interpretasi }\end{array}$ \\
\hline & Baik Sekali \\
$81 \%-100 \%$ & Baik \\
$61 \%-80 \%$ & Cukup \\
$41 \%-80 \%$ & Kurang \\
$21 \%-40 \%$ & KurangBaik \\
$0 \%-20 \%$ & \\
& \\
\hline
\end{tabular}

Sedangkan untuk menilai peningkatan hasil belajar siswa sebelum dan sesudah mendapatkan pembelajaran menggunakan media MOONSTAR (monopoli super pintar) dengan uji $\mathrm{N}$-gain.

Rumus:

$\mathrm{g}=\frac{\text { skor postest-skor pretest }}{\text { skor ideal-skor pretest }}$

Jika $\mathrm{g}<0,3$, maka $\mathrm{N}$-gain yang dihasilkan termasuk kategori rendah

Jika $0,3 \leq \mathrm{g}<0,7$, maka $\mathrm{N}$-gain yang dihasilkan termasuk kategori sedang

Jika $\mathrm{g} \geq 0,7$ maka $\mathrm{N}$-gain yang dihasilkan termasuk kategori tinggi.

\section{PEMBAHASAN}

Penelitian yang dilakukandi SD Negeri Tegalarum 2 Mranggen dikelas IV yang 
berjumlah 30 siswa ini sebelumnya sudah di persiapkan, persiapan tersebut dilakukan agar penelitian berjalan dengan baik dan memperoleh hasil yang di harapkan. Persiapan yang dilakukan penulis adalah melakukan observasi dan wawancara di sekolah guna mengumpulkan data atau informasi yang ada disekolah, khususnya pada materi perkembangan teknologi produksi, komunikasi dan transportasi.

Dalam studi pendahuluan di dapat permasalahan yaitu bahwa mata pelajaran IPS merupakan mata pelajaran yang kurang dipahami oleh siswa pada materi perkembangan teknologi produksi, komunikasi, dan transportasi, di karenakan kurangnya media pembelajaran yang membuat siswa mearasa bosan. Siswa cenderung kurang memperhatikan ketika guru menggunakan metode ceramah.

Pengembangan media pembelajaran MOONSTAR (Monopoli Super Pintar) berdasarkan permainan monopoli yang dilakukan oleha nak-anak, Dengan inovasi pengembanngan media pembelajaran tersebut diharapkan pembelajaran akan menarik bagi siswa dan siswa akan memahami materi dengan baik.

Media MOONSTAR (Monopoli Super Pintar) sebuah media yang terbuat dari MMT yang berukuran 2,5 $\mathrm{m}$ x 2,5 m. Media moonstar (monopoli super pintar) ini dikemas dalam sebuah tas sehingga memudahkan dalam hal penyimpanan serta memudahkan dalam hal membawa atau memindahkan MOONSTAR (Monopoli Super Pintar) jika akan digunakan atau pun sesudah digunakan. Kotak monopoli terdiri dari soal-soal yang menyangkut materi Perkembangan Teknologi Produksi, Komunikasi, dan Transportasi. Setelah selesai pada tahap studi pengembangan maka akan dilanjutkan pada tahap studi pengujian di lapangan, yang nanti akan diujikan pada siswa kelas IV SD Negeri Tegalarum 2 Mranggen. Validasi merupakan salah satu langkah yang harus dilakukan dalam penelitian dan pengembangan. Pada tahap ini media MOONSTAR (Monopoli Super Pintar) akan dinilai untuk menentukan apakah media ini sudah layak digunakan atau belum untuk dilakukan uji penelitian.

Dibawah ini merupakan hasil akhir dari validasi media:

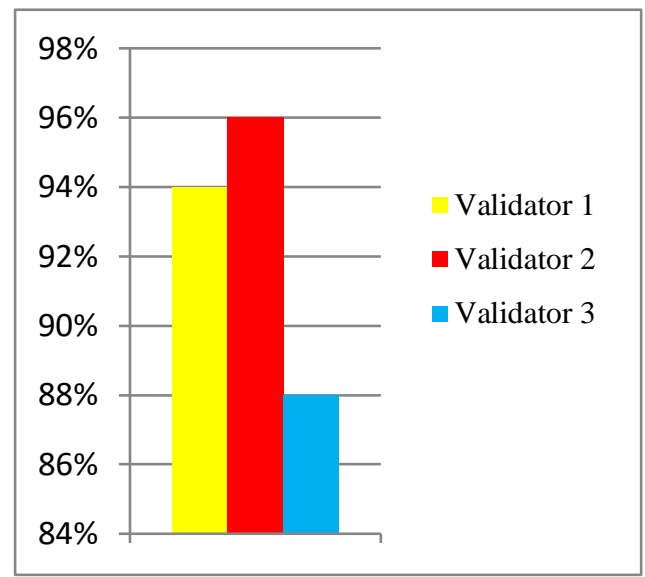

Gambar 1.1 Hasil Akhir Validasi Media

Berdasarkan hasil akhir validasi media tersebut memperoleh hasil rata-rata $92 \%$.

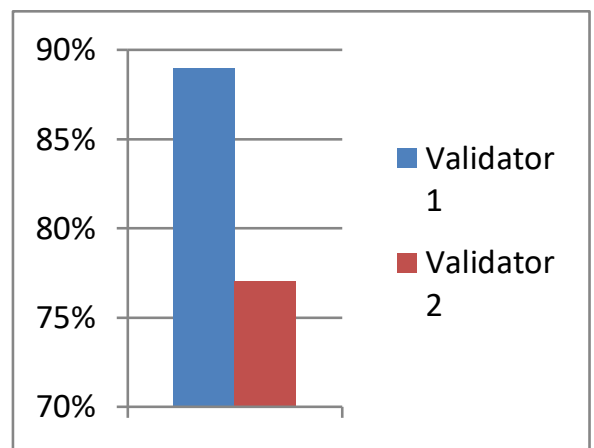

Gambar 1.2 Hasil Akhir Validasi Materi

Dapat disimpulkan bahwa media layak digunakan dalam penelitian dilapangan. Sedangkan untuk hasil angket respon guru sebesar $91 \%$ yang merupakan perhitungan dari aspek penilaian yaitu: indikator kesesuaian, indikator kelayakan, kontribusi produk, keunggulan produk, dan indikator penyajian. 


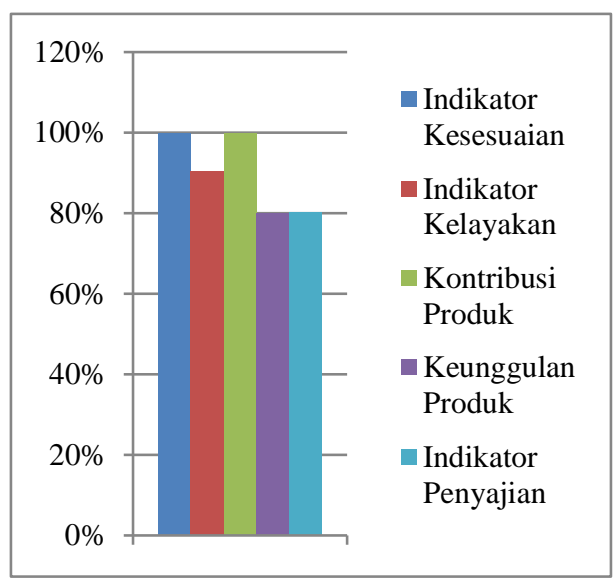

Gambar 1.3 Angket Respon Guru Terhadap Media MOONSTAR (Monopoli Super Pintar)

Sedangkan hasil respon siswa sebesar 97\% dari perhitungan jawaban "Ya" atau "Tidak" sesuai dengan angket respon siswa mengenai media MOONSTAR (Monopoli Super Pintar).

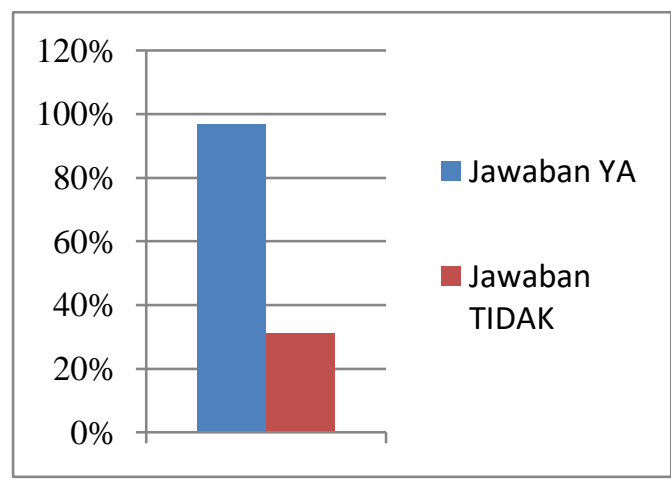

Gambar 1.4 Angket Respon Siswa Terhadap Media MOONSTAR (Monopoli Super Pintar)

Untuk hasil evaluasi dari siswa kelas IV yang berjumlah 30 siswa menggunakan media pembelajaran MOONSTAR (Monopoli Super Pintar) memberikan hasil positif yaitu dengan memperoleh nilai ratarata gain sebesar 0,51 dengan kategori sedang.

Tabel 1.2 Hasil Nilai Rata-rata Siswa

\begin{tabular}{|c|c|c|c|}
\hline $\begin{array}{c}\text { Nilai Pre } \\
\text { test }\end{array}$ & $\begin{array}{c}\text { Nilai } \\
\text { Post test }\end{array}$ & N-gain & $\begin{array}{c}\text { Kriteria } \\
\text { N-gain }\end{array}$ \\
\hline 63 & 82 & 0,51351 & Sedang \\
\hline
\end{tabular}

Dapat disimpulkan bahwa media MOONSTAR (Monopoli Super Pintar) layak digunakan sebagai media pembelajaran dan media MOONSTAR (Monopoli Super Pintar) berbantu model pembelajaran talking stcik lebih efektif dari pembelajaran konvensional pada mata pelajaran IPS materi Perkembangan Teknologi Produksi, Komunikasi, dan Transportasi untuk siswa kelas IV Sekolah Dasar.

\section{SIMPULAN}

Pengembangan media MOONSTAR (Monopoli Super Pintar) pada pembelajaran IPS materi Perkembangan Teknologi Produksi, Komunikasi, dan Transportasi semester II kelas IV Sekolah Dasar adalah sebagai berikut: Analysis, mengidentifikasi kebutuhan siswa sehingga ditemukan masalah, Design, menggunakan masalah sebagai landasan merancang media MOONSTAR (Monopoli Super Pintar), Development, menetapkan tujuan pembelajaran, Mengidentifikasi Sandar Kompetensi dan Kompetensi Dasar serta memproduksi media pembelajaran, Implementation, melaksanakan pembelajaran menggunakan media MOONSTAR (Monopoli Super Pintar) yang sebelumnya media melalui proses validasi oleh ahli media dan materi pembelajaran, Evaluation, melalukakan evaluasi produk yang dikembangkan.

Dan dari pengujian yang dilakukan oleh dosen ahli media pembelajaran dengan presentase $92 \%$ dengan kategori baik sekali, presentase ahli materi pembelajaran yaitu sebanyak $83 \%$ dengan kategori baik sekali, untuk angket respon guru memiliki skor keidealan sebesar $91 \%$ dengan kategori baik sekali dan angket respon siswa memiliki skor keidealan sebesar 97\% dengan kategori baik sekali. Hasil evaluasi dari 30 siswa mendapat perolehan nilai rata-rata gain sebesar 0,51 dengan kategori sedang sehingga dapat dikatakan bahwa media MOONSTAR (monopoli super pintar) berbantu model pembelajaran talking stick lebih efektif dari pembelajaran konvensional 
pada mata pelajaran IPS dengan materi perkembangan teknologi produksi, komunukasi, dan transportasi untuk siswa kelas IV SD.

\section{DAFTAR PUSTAKA}

Arsyad, Azhar. 2011. Media Pembelajaran. Jakarta: PT Raja Grafindo Persada.

Badru Zaman. 2006. Pengembangan Alat Permainan Edukatif Untuk Anak Taman KanakKanak. Dalam: http://badruzaman.staff.upi.edu/files/2011/12/materi-media-paudupi.pdf. Di akses pada tanggal 25 Januari 2018.

Daryanto. 2016. Media Pembelajaran. Yogyakarta: Gava Media.

Huda, Miftahul. 2017. Model-Model Pengajaran dan Pembelajaran. Yogyakarta: Pustaka Pelajar..

Permendiknas. 2007. Standar Proses Untuk Satuan Dasar dan Menengah. Dalam: https://dayatfarras.files.wordpress.com/2011/07/standar-proses-permen-412007.doc\&prev. Di akses pada tanggal 26 Januari 2018.

Sapriya, M.ed. 2009. Pendidikan IPS Konsep dan Pembelajaran. Bandung: PT Remaja Rosdakarya

Sugiyono. 2015. Metode penelitian pendidikan Pendekatan Kuantitatif, Kualitatif, dan RnD. Bandung: Alfabeta

Sundayana, M.ed. 2009. Statistika Penelitian Pendidikan. Bandung: Alfabeta

Suprapto, N.A. 2013. Permainan Monopoli sebagai Media Untuk Meningkatkan Minat Belajar Tata Boga di SMA. Jurnal Ilmiah Guru, No. 1, Tahun XVII, Mei 2013.

Soegeng, A.Y. 2016. Dasar-dasarPenelitian.Yogyakarta: Magnum Pustaka Utama.

Undang-undangRepublik Indonesia. 2003. Di aksespadatanggal 26 Januari 2018. Dalam: https://kemenag.go.id/file/dokumen/UU2003.pdf. 